\title{
Fatigue failure load of zirconia-reinforced lithium silicate glass ceramic cemented to a dentin analogue: Effect of etching time and hydrofluoric acid concentration
}

\author{
Jaiane Bandoli Monteiro $^{\mathrm{a}}$, Marcelo Gallo Oliani ${ }^{\mathrm{a}}$, Luis Felipe Guilardi ${ }^{\mathrm{b}}$, Catina Prochnow ${ }^{\mathrm{b}}$, \\ Gabriel Kalil Rocha Pereira ${ }^{\text {b,c }}$, Marco Antonio Bottino ${ }^{a}$, Renata Marques de Melo ${ }^{a}$, \\ Luiz Felipe Valandro ${ }^{\text {b,* }}$
}
a PhD Post-Graduate Program in Restorative Dentistry (Prosthodontics Units), Univ. Estadual Paulista (UNESP), Institute of Science and Technology at Sao Jose dos Campos, Sao Jose dos Campos, Sao Paulo State, Brazil
b PhD Post-Graduate Program in Oral Science (Prosthodontic Units), Faculty of Odontology, Federal University of Santa Maria, R. Floriano Peixoto, 1184, 97015-372 Santa Maria, Rio Grande do Sul, Brazil
${ }^{c}$ MSciD Graduate Program, School of Dentistry, Meridional Faculty - IMED, Passo Fundo, Rio Grande do Sul, Brazil

\section{A R T I C L E I N F O}

\section{Keywords:}

Glass ceramics

Surface conditioning

Bonding

Cementation

Topography

Fatigue

\begin{abstract}
A B S T R A C T
This study aimed to evaluate the effect of etching time and hydrofluoric acid (HF) concentration on the fatigue failure load and surface characteristics of zirconia-reinforced lithium silicate glass (ZLS) ceramic cemented to a dentin-like, fiber reinforced epoxy resin. Ceramic (Suprinity, VITA) (1.0 mm thick) and epoxy resin (2.5 mm thick) discs (10 mm diameter) were produced. The bonding surface of the ceramic samples was nonetched (control group), or etched for 30,60 or $90 \mathrm{~s}$ by $5 \%$ or $10 \% \mathrm{HF}$. The epoxy resin discs were etched by $10 \% \mathrm{HF}$ for $30 \mathrm{~s}$ followed by the application of an adhesive material (Single Bond Universal, 3M ESPE). Pairs of ceramic/ epoxy resin discs were cemented with a dual cure resin cement. The fatigue failure load was determined by the staircase method (500,000 cycles at $20 \mathrm{~Hz}$; initial load $=925 \mathrm{~N}$; step size $=45 \mathrm{~N})$. In $10 \% \mathrm{HF}$ the etching time was shown to influence the fatigue failure load, which increased as the etching time increased ( $30 \mathrm{~s}<60 \mathrm{~s}<90 \mathrm{~s}$ ), and in 5\% HF the fatigue failure load was not shown to be affected by the etching time; the lowest fatigue failure loads were produced in the control group without ceramic etching followed by $10 \% \mathrm{HF}$ acid etching for $30 \mathrm{~s}$. Topography analysis showed variations based on the etching protocols. All fractures (radial cracks) were shown to originate from defects at the ceramic surface on the cementing interface. For fatigue loading improvements of ZLS ceramic, $10 \% \mathrm{HF}$ acid etching for $90 \mathrm{~s}$ and silanization of the ceramic surface is recommended.
\end{abstract}

\section{Introduction}

Recently, zirconia-reinforced lithium silicate glass (ZLS) ceramics were introduced on the market for CAD/CAM restorations, such as Vita Suprinity (Vita Zahnfabrik, Bad Säckingen, Germany), composed of a synthetic glass matrix with zirconia crystals (56-64\% silicon dioxide, $15-21 \%$ lithium oxide, $8-12 \%$ zirconia, and other components, e.g. pigments) (Vita Suprinity, 2013; Gracis et al., 2015). It combines excellent optical and mechanical properties, with flexural strength of approximately $440 \mathrm{MPa}$ (Elsaka and Elnaghy, 2016), and has been considered for monolithic full-contour restorations (Rinke et al., 2016a, 2016b).

An important aspect required for the success of such restorations is the establishment of proper adhesion between substrate and adherent (Tsujimoto et al., 2017). In this sense, the gold-standard protocol for resin bonding to glass ceramics is the etching with hydrofluoric acid (HF) followed by the application of a silane coupling agent (chemical and micro-mechanical bond) (Sattabanasuk et al., 2016; Sato et al., 2016). Variations in HF acid etching (for instance, time and concentration) have been shown to change the surface micro-morphology of glass ceramics (surface defect population) (Traini et al., 2016) and resin adhesion (Leite et al., 2013; Venturini et al., 2015b), being the

\footnotetext{
* Corresponding author.

E-mail addresses: jaiane.monteiro@ict.unesp.br (J.B. Monteiro), marcelo.oliani@ict.unesp.br (M.G. Oliani), luisfguilardi@hotmail.com (L.F. Guilardi),

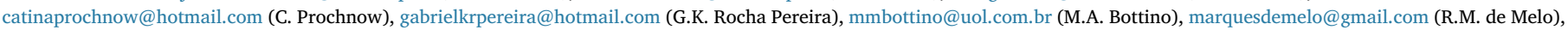
lfvalandro@hotmail.com (L.F. Valandro).
} 
increase in HF acid concentration and etching time associated with an increase on surface area available to adhesion with resin cement and a decreasing on contact angle values (Ozcan and Valittu, 2003; Venturini et al., 2015b; Sato et al., 2016).

Even that rougher surfaces are related to better adhesive potential, HF over-etching (e.g., increased time and concentration) is reported as detrimental to flexural strength as well as the fatigue behavior of glass ceramics (Addison et al., 2007; Hooshmand et al., 2008; Zogheib et al., 2011; Venturini et al., 2015a; Venturini et al., 2017). However, some reports have shown that adhesively cementation is able to promote a strengthening of the assembly (May et al., 2012; Posritong et al., 2013; Venturini et al., 2017), filling up the defects and flaws produced by HF acid etching (Anusavice and Hojjatie, 1992).

Clinically, ceramic restorations are susceptible to fatigue failure in response to an environment in the presence of moisture and cyclic masticatory forces (Gonzaga et al., 2011; Morimoto et al., 2016). Hence, fatigue failure may be defined as the cumulative damage triggered by cyclic forces, resulting in slow-crack growth of defects that will lead to catastrophic failure of a restoration under loads below the normal characteristic strength of a specific material (Wiskott et al., 1995; May et al., 2015). Although, the fatigue behavior of ZLS ceramics, including the effect of different etching protocols on the fatigue load bearing capability of the material, has not been studied. Thus, the question is: do the surface topographic variations of ZLS glass ceramic affect the fatigue behavior of this material adhesively cemented?

Thus, this study aimed to elucidate and compare the effect of different HF acid concentrations and etching time on the surface characteristics and fatigue failure load of a ZLS ceramic cemented to a dentin analogue. The null hypotheses were: (1) mean fatigue failure loads will not be influenced by the etching time; (2) HF acid concentrations will not affect the mean fatigue failure loads.

\section{Materials and methods}

\subsection{Specimen assembly description}

A simplified tri-layer setup was designed, as presented by Chen et al. (2014), to simulate an occlusal restoration for a posterior tooth (molar). ZLS discs, reproducing the occlusal restoration, were cemented on a glass fiber reinforced epoxy resin disc, which simulated dentin. The discs were $10 \mathrm{~mm}$ in diameter, the average dimension of molars (Ferrario et al., 1999). The bonded tri-layer discs had a final thickness of $3.5 \mathrm{~mm}$, equivalent to the average thickness from pulp wall to occlusal surface (Sulieman et al., 2005; Harris and Hicks, 1998).

\subsection{Ceramic specimens manufacturing}

Pre-fabricated ceramic blocks of Vita Suprinity (Vita Zahnfabrik H. Rauter GmbH \& Co., Bad Säckingen, Germany; Lot No. 49142) were shaped into cylinders (10 $\mathrm{mm}$ in diameter) using silicon carbide (SiC) papers with 180-grit sandpaper in a polishing machine (Ecomet 250 Grinder Polisher, Buehler, Illinois, USA). The cylinders were cut with a diamond blade under constant water-cooling (Isomet 1000, Buehler, Illinois, USA), resulting in 150 discs with a standard thickness of $1.1 \mathrm{~mm}$. The specimens were crystallized in a furnace according to the manufacturer's instructions (VACUMAT $6000 \mathrm{MP}$, VITA; $840{ }^{\circ} \mathrm{C}, 8 \mathrm{~min}$ vacuum). The 'occlusal' surface of the discs (opposite the cementation surface) was polished with $\mathrm{SiC}$ paper of increasing grit-size (600-, 800and 1200-grit) until a final thickness of $1.0 \mathrm{~mm}$ was achieved.

\subsection{Epoxy resin discs manufacturing}

The used epoxy resin sheet $(150 \mathrm{~mm} \times 350 \mathrm{~mm}$, $2.5 \mathrm{~mm}$ thick) was acquired from Carbotec GmbH \& Co. KG. (Königs Wusterhausen; Lot No. 295795). The aforementioned ceramic specimens methodology was used for shaping the epoxy resin into cylinders (10 $\mathrm{mm}$ in diameter).

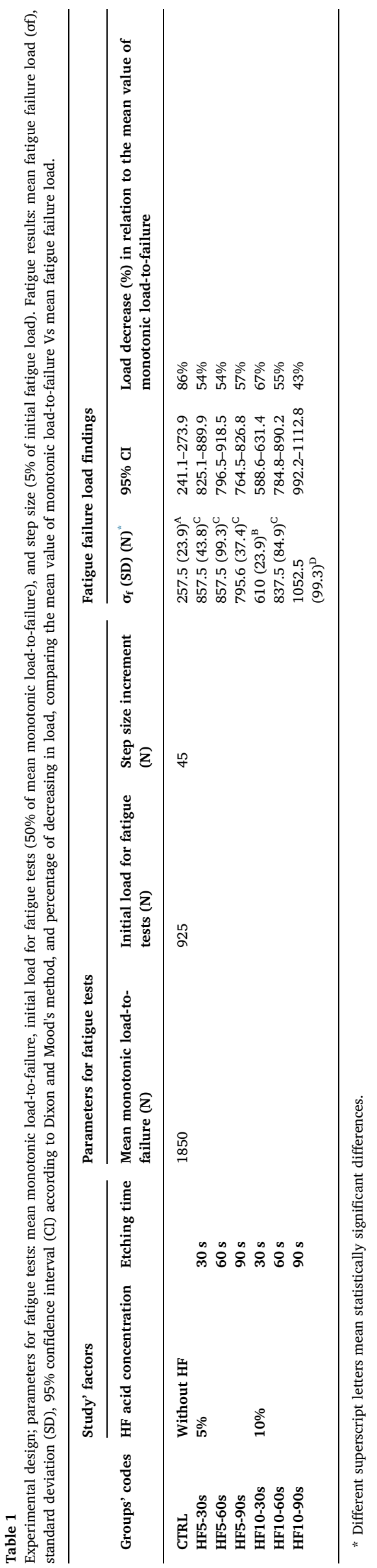




\subsection{Experimental design - Conditioning and cementation procedures}

Pairs of ceramic and epoxy resin discs were randomly assigned into seven groups (Table 1). The ceramic surfaces of the control (CTRL) group were kept as crystallized, without any surface treatment. The remaining ceramic discs were etched with $5 \%$ or $10 \%$ hydrofluoric acid (Maquira Ind. Prod. Odontologicos Ltda, Maringa, PR, Brazil; Lot No. 039816 and 036016 , respectively) for $30 \mathrm{~s}, 60 \mathrm{~s}$, or $90 \mathrm{~s}$ (Table 1). After etching, the discs were washed and rinsed for $30 \mathrm{~s}$ in water, gently air dried, and cleaned with distilled water in an ultrasonic bath $(5 \mathrm{~min})$ to remove any residual acid. The ceramic samples from the CTRL group were also cleaned under these conditions.

The cementation surface of the epoxy resin discs, including the CTRL group, were etched with $10 \% \mathrm{HF}$ acid for $30 \mathrm{~s}$, followed by ultrasonic cleaning in distilled water (5 min). After etching, a thin layer of adhesive (Single Bond Universal Adhesive, $3 \mathrm{M}$ Deutschland $\mathrm{GmbH}$, Seefeld, Baviera, Germany; Lot No. 594356) was applied for $20 \mathrm{~s}$ (with microbrush) on both ceramic and epoxy resin substrates, followed by $5 \mathrm{~s}$ of gentle air-drying.

A dual resin cement (RelyX Ultimate Clicker Adhesive Resin Cement, $3 \mathrm{M}$ ESPE; Lot No. 1620100708) was manipulated as recommended by the manufacturer and applied to the center of the ceramic and epoxy discs. The discs were joined and placed in a specific device to apply a standard load of $7.5 \mathrm{~N}$ on the occlusal surface of the ceramic, promoting uniform cement spreading. After the excess cement was removed using a microbrush, LED light curing (high intensity of $1200 \mathrm{~mW} / \mathrm{cm}^{2}$; wavelength ranging from 440 to $480 \mathrm{~nm}$ - Radii-Cal, SDI, Dublin, Ireland) was executed for $40 \mathrm{~s}$ on the occlusal surface of the ceramic, followed by $10 \mathrm{~s}$ in each bonded interface side $\left(0^{\circ}, 90^{\circ}\right.$, $180^{\circ}, 270^{\circ}$ ). The specimens were stored in distilled water in a sealed vessel at room temperature for two days prior to fatigue testing.

\subsection{Fatigue failure load tests}

The specimens were subjected to an accelerated fatigue test (staircase method) (Instron ElectroPuls E3000, Instron Corporation, Norwood, MA, United States); a maximum error of $25 \mathrm{~N}$ is expected for a $5 \mathrm{kN}$ load cell (estimated error of $0.5 \%$ load cell capacity). A $40 \mathrm{~mm}$ diameter stainless-steel sphere (Fig. 1; Kelly et al., 2010; Anami et al., 2016; Campos et al., 2017) was used to apply the load in the center of the 'occlusal' ceramic surface stabilized in a flat steel base under water. An attached cylindrical metal ring was used to facilitate specimen positioning, and to ensure the load application occurred in the center of each specimen.

According to Kelly et al. (2010), the fatigue tests under water with a

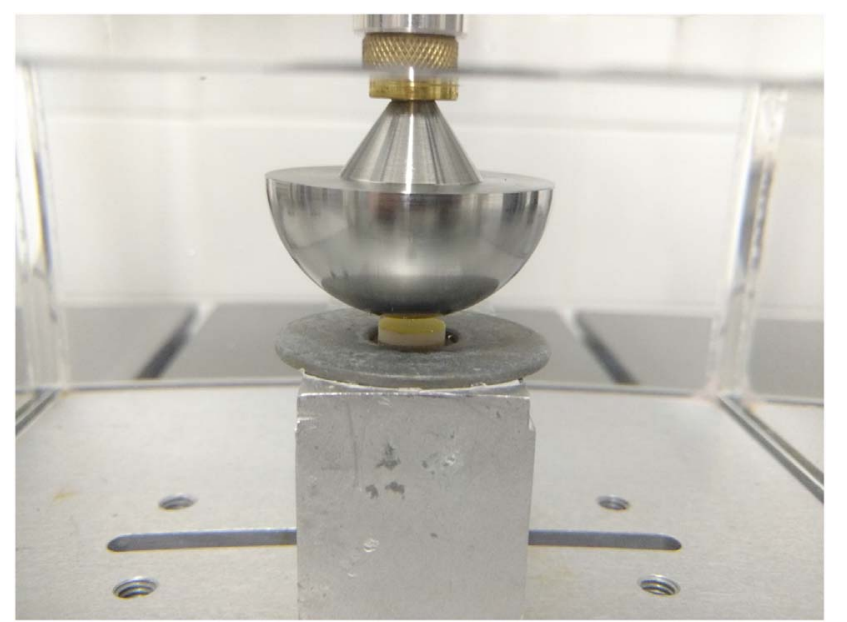

Fig. 1. Representative image of stainless-steel sphere ( $40 \mathrm{~mm}$ in diameter) used to apply the load at the center of the samples. sphere of $40 \mathrm{~mm}$ more closely simulate the clinical load routinely applied to dental ceramic restorations. This experimental set up generates a surface of contact instead of a single point of contact, which could result in higher stress concentration. This assembly generates crack propagation (subsurface radial cracks) in the cementing interface; the pattern most often reported in clinically failed specimens. Before all fatigue tests, an adhesive tape $(110 \mu \mathrm{m})$ was fixed on the occlusal side of each specimen to improve the contact with the piston, promoting better stress distribution (Wachtman et al., 1972) and preventing contact surface damage, which could result in cone crack propagation. An additional thin sheet of a non-rigid material (cellophane, $2.50 \mu \mathrm{m}$ ) was placed between the piston and the specimen to enhance stress distribution (ISO, 6872-2008).

The initial maximum load and the step size for fatigue tests were determined based on the mean of five specimens subjected to monotonic load to failure test in an universal testing machine (EMIC DL 2000, Sao José dos Pinhais, Brazil), which applied an increasing load $(1 \mathrm{~mm} / \mathrm{min})$ until a radial crack fracture occurred. Cyclic failure loads (500,000 cycles at $20 \mathrm{~Hz}$ ) were applied with amplitudes ranging from a minimum of $10 \mathrm{~N}$ (to maintain the piston in close contact with the specimen) to the maximum load for every cycle using the staircase method described by Collins (1993). The first specimen of each group was tested at an initial load level close to the estimated fatigue failure load (approximately $60 \%$ of the mean monotonic load to failure, $925 \mathrm{~N}$ ) until it either failed or run-out (survival) at the predetermined cycles (5 $\times 10^{5}$ total). A step size load of $5 \%(45 \mathrm{~N})$ of the initial load level was applied up or down to the next specimen, according to survival or failure of the previous specimen. This procedure was repeated until at least 15 samples per group, previously described by Collins (1993) as the minimum number of tests necessary to obtain a precise estimation using this methodology.

\subsection{Topographic analysis}

Additional ceramic specimens $(\mathrm{n}=2)$ were produced as aforementioned to be analyzed under scanning electron microscope (SEM) (Inspect S50, FEI, Brno, Czech Republic) under $3000 \times$ magnification.

\subsection{Fractographic analysis}

After the fatigue tests, all specimens were evaluated on a binocular stereomicroscope (Discovery V20, Carl Zeiss, Gottingen, Germany) to determinate the crack direction, and then sectioned into two halves perpendicularly to the direction of cracks with a diamond blade under constant water-cooling (Isomet 1000). The samples were analyzed with a stereomicroscope to identify the origin and propagation of the cracks. Some representative fractures were also examined under SEM at $\times 500$, $\times 1000$, and $\times 2500$ magnifications.

\section{Results}

\subsection{Fatigue failure load tests (staircase method)}

The mean fatigue failure load (of), standard deviation (SD), and 95\% confidence interval were calculated using the Dixon and Mood method, which involves the maximum-likelihood estimation (overlapping confidence intervals) and assumes the data follows a normal distribution (Collins, 1993), a procedure previously described by Fraga et al. (2016), Pereira et al. (2016) and Villefort et al. (2017). Parameters for the fatigue tests and results are presented in Table 1. The pattern of runouts (survivals) and failures for each group are described in Fig. 2.

The CTRL group presented the lowest fatigue failure load. Increasing the etching time in $10 \% \mathrm{HF}$ increased the fatigue load of each time group (HF10-30 $s<$ HF10-60 $s<$ HF10-90 s). The fatigue failure load under $5 \% \mathrm{HF}$ etching was not affected by the duration of 


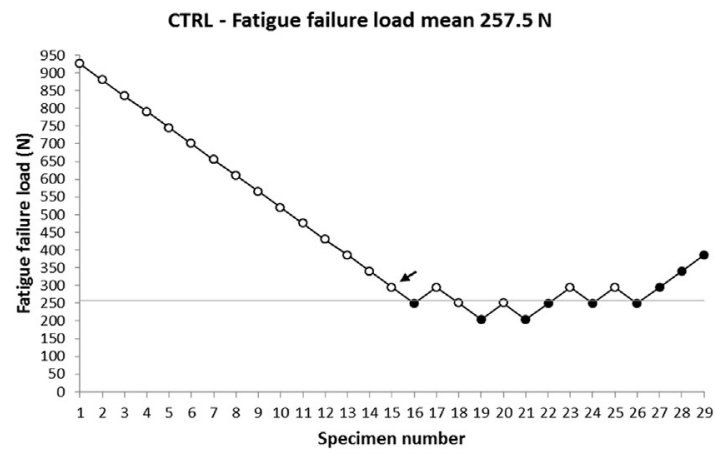

A

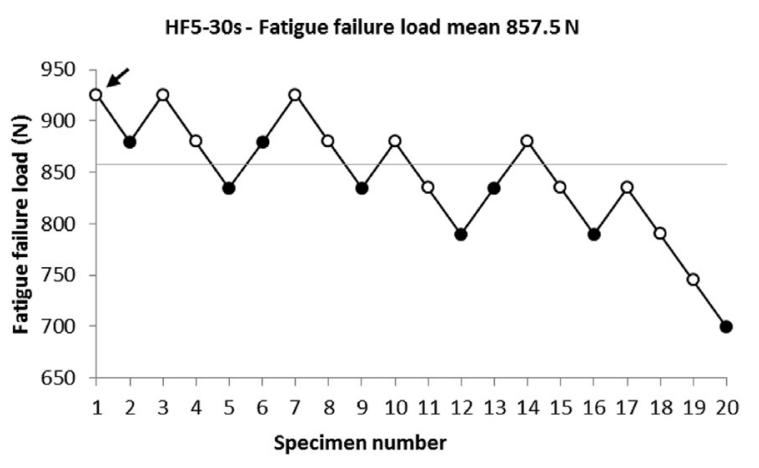

B

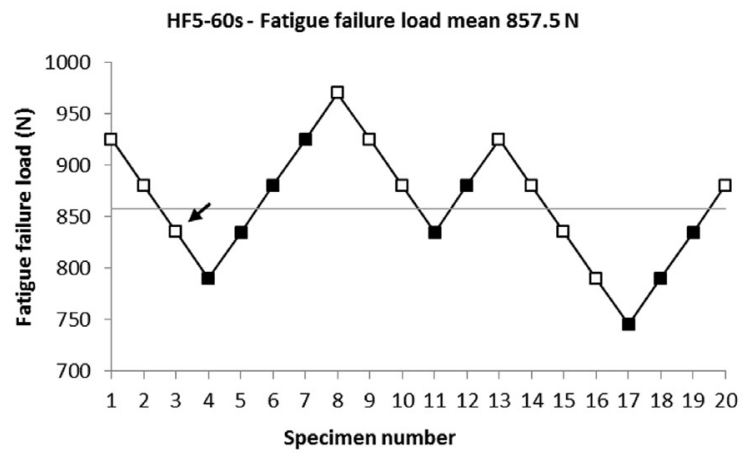

C

HF5-90s - Fatigue failure load mean 795.6 N

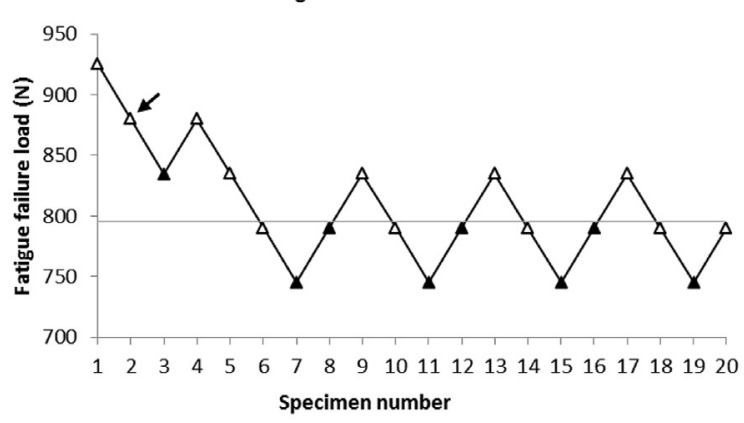

D

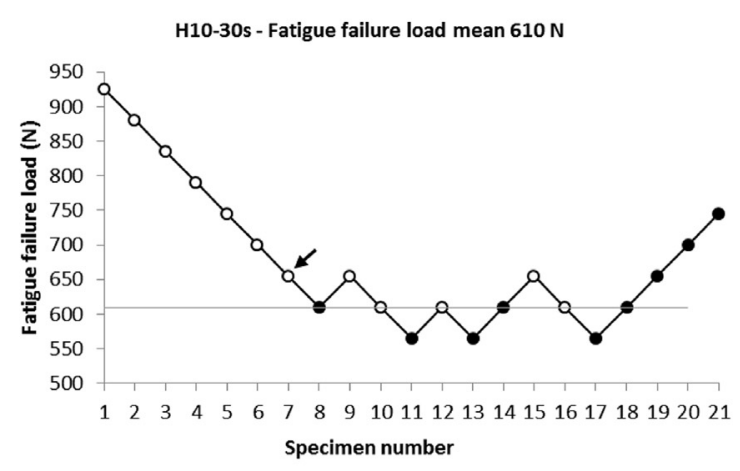

E

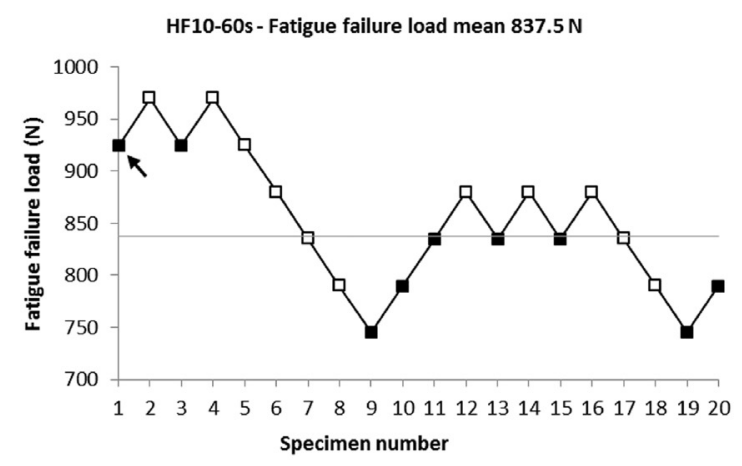

F

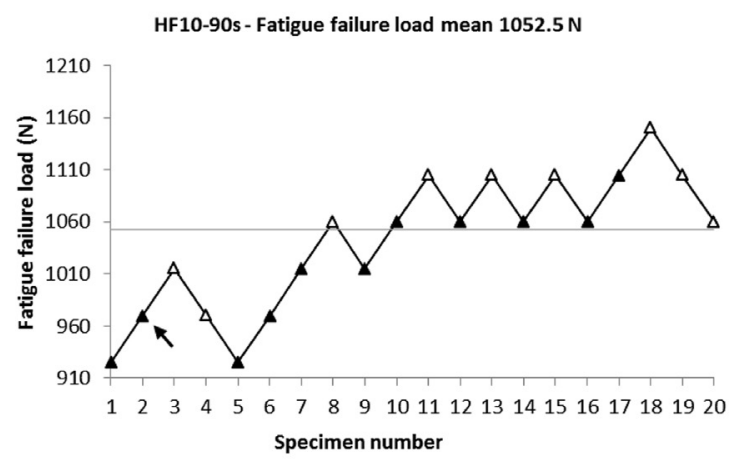

G

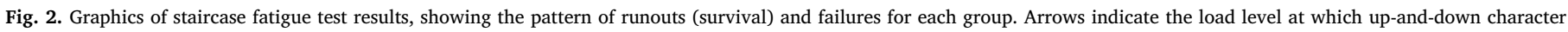
started, i.e., when the first reversal occurred. Horizontal lines indicate mean fatigue failure load, filled scorers represent runout, and empty scorers represent failures.

etch (HF5-30 s = HF5-60 s = HF5-90 s) (Table 1). After $30 \mathrm{~s}$ of etching, $5 \% \mathrm{HF}$ resulted in a higher mean failure load than $10 \% \mathrm{HF}$ (Table 1), while $10 \%$ HF was higher than $5 \%$ when etching for $90 \mathrm{~s}$. Under $60 \mathrm{~s}$ of etching, no statistical difference between the acid concentration and fatigue failure load was observed. The samples etched in
$10 \% \mathrm{HF}$ for $90 \mathrm{~s}$ presented the highest values and the lowest decrease in fatigue failure load in relation to the initial load to fracture $(43 \%$ decrease), while the CTRL group presented a decrease of almost $86 \%$ (Table 1). 


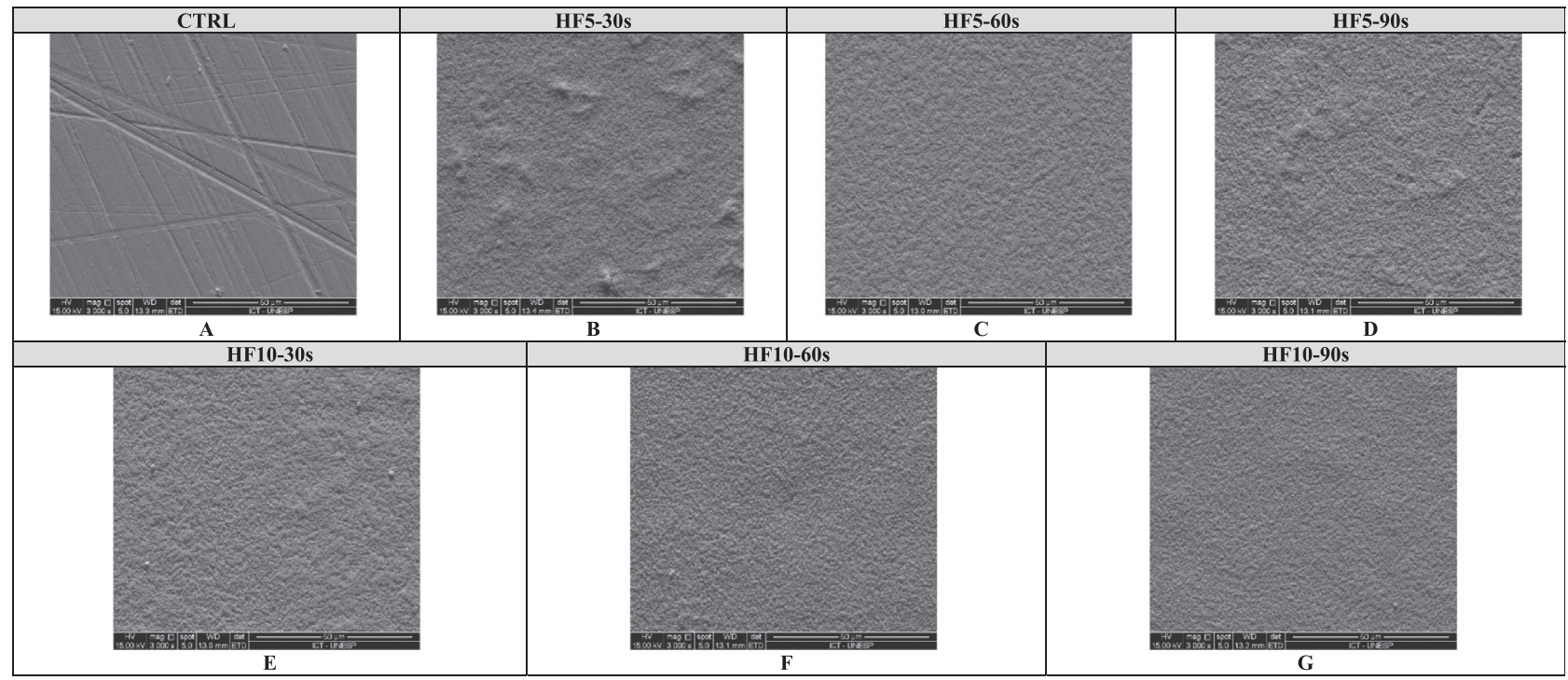

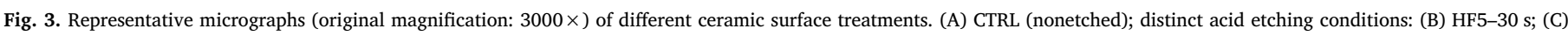
HF5-60 s; (D) HF5-90 s; (E) HF10-30 s (F) HF10-60 s; (G) HF10-90 s.

\subsection{Topographic analysis}

Fig. 3 shows SEM images of the ceramic surfaces. The untreated ceramic surface is homogeneous and smooth, presenting scratches from the cut procedure. The etched ceramic surfaces show an increase in roughness and surface area under HF etching conditions, regardless of acid concentration and application time.

\subsection{Fractographic analysis}

The fractographic analysis under a light microscope showed all failures started as radial cracks from the cementation surface and Hertzian cone cracks were not observed. Fig. 4 shows the representative
SEM micrographs of the fractured surfaces, depicting the cracks propagated in a perpendicular direction to the main tensile stress and fracture originated at an initial superficial defect localized on the tensile surface of the ceramic (cementation surface). The cracks were more prominent on surfaces etched with $10 \% \mathrm{HF}$ acid (regardless of etching time).

\section{Discussion}

In this current study, the null hypothesis that the etching time would not affect the fatigue behavior of a ZLS glass ceramic was partially rejected. There was no influence of etching time for the 5\% HF acid (statistically similar results), while the etching time had statistically
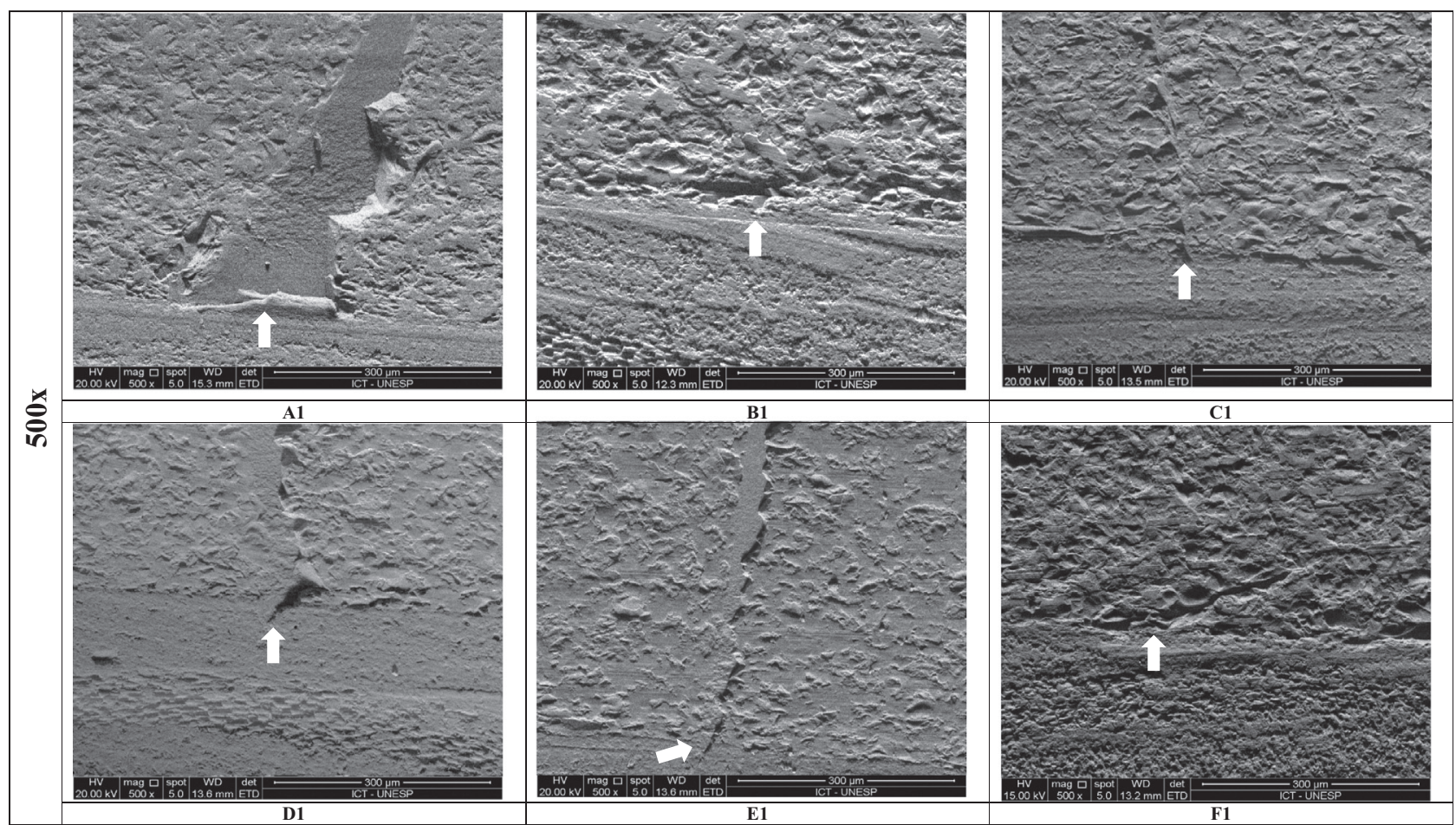

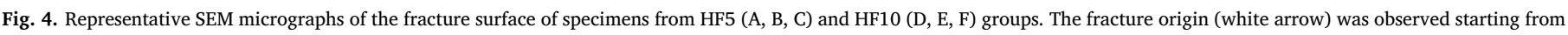
the etched surfaces under tensile stress (intaglio surface of ceramic discs). 


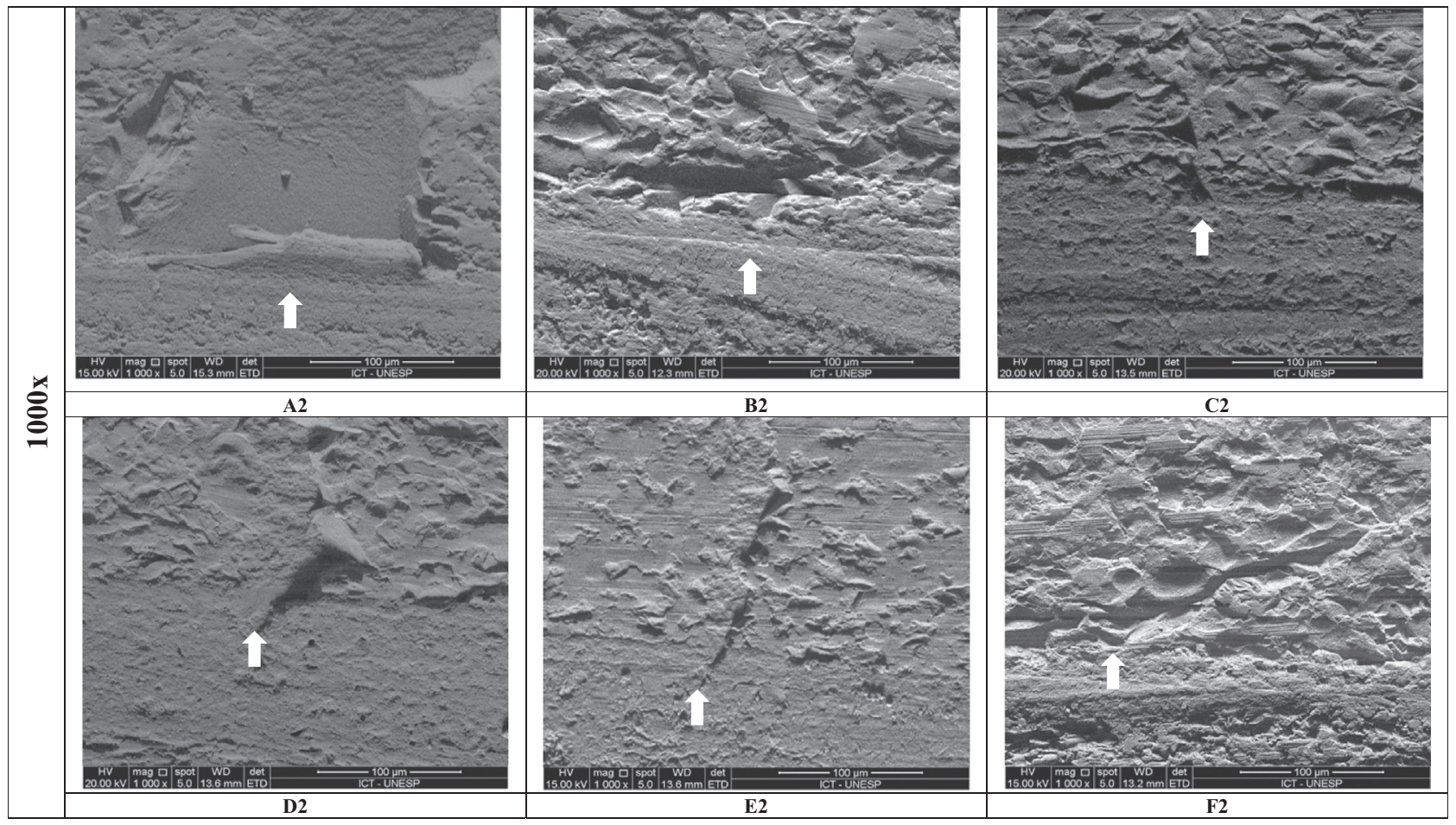

Fig. 4. (continued)

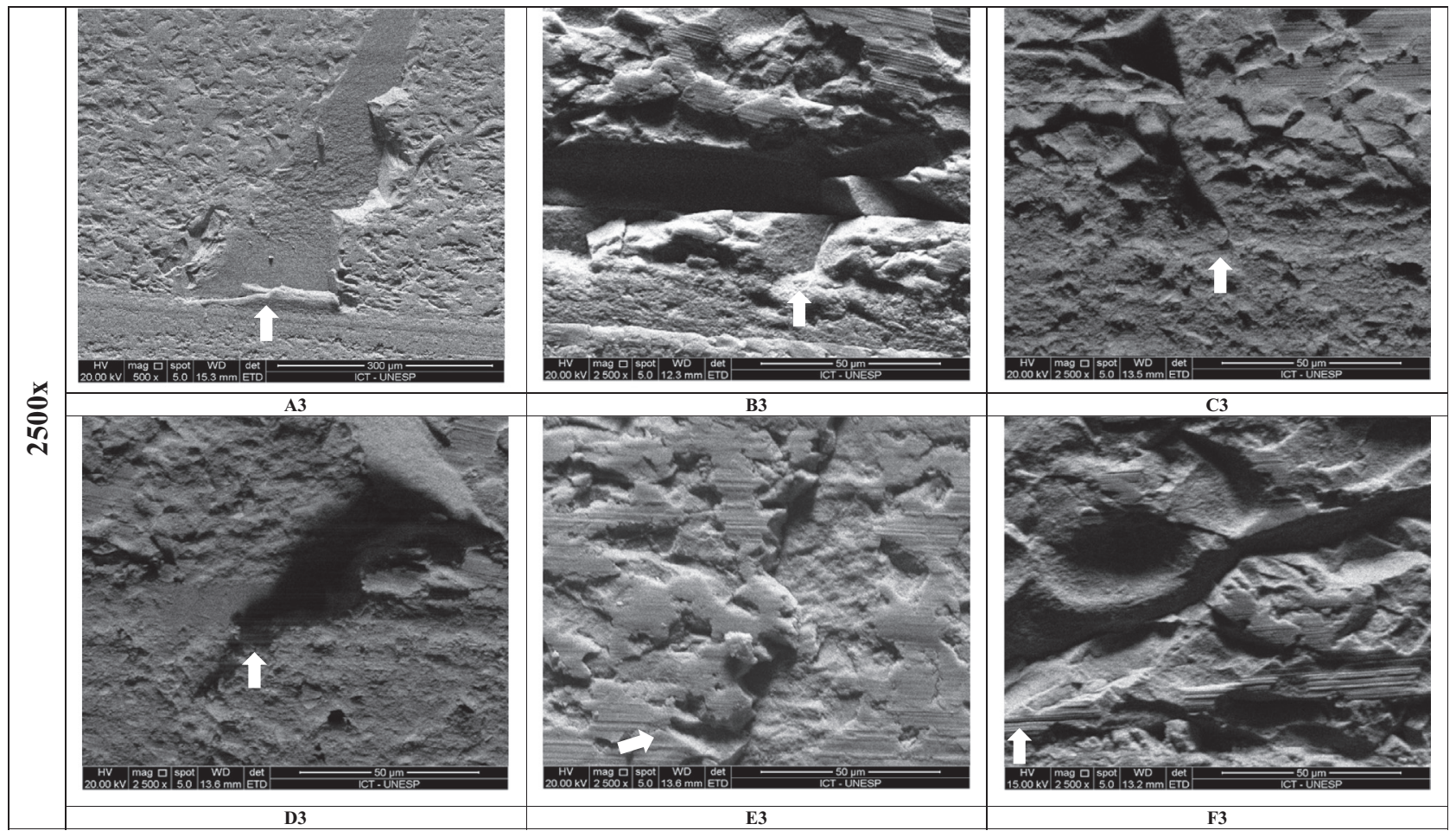

Fig. 4. (continued)

significant effects in 10\% HF (HF10-30 s < HF10-60 s < HF10-90 s) (Table 1). Regarding the influence of HF acid concentration, $30 \mathrm{~s}$ etch with $5 \% \mathrm{HF}$ led to higher mean fatigue failure load than $10 \% \mathrm{HF}$ (HF5-30 s > HF10-30 s), and opposite trend was observed for a $90 \mathrm{~s}$ etch (HF5-90 s < HF10-90 s); the $60 \mathrm{~s}$ etch demonstrated statistically similar failure loads in both HF acid concentrations. Thus, the second null hypothesis, that $\mathrm{HF}$ acid concentration would not affect the results, was also partially rejected.
As stated previously, ZLS ceramic consists of a particularly fineparticle structure containing lithium silicate crystals with average size of $0.5 \mu \mathrm{m}$ and a glassy matrix containing $10 \%$ highly dispersed zirconia crystals (Zimmermann et al., 2013). When conditioned by HF acid, the glassy matrix undergoes a process of selective dissolution and exposure of the crystalline content (Ramakrishnaiah et al., 2016; Traini et al., 2016). The time of HF etching significantly alters the topographic patterns (Ramakrishnaiah et al., 2016; Sattabanasuk et al., 2016; Traini 
et al., 2016), creating porosities/defects of varying depth and width (Della Bona and Anusavice, 2002; Sato et al., 2016) and an increased surface area for micromechanical bonding with resin cement (Aboushelib et al., 2014).

In this study, HF etching was effective in promoting surface alterations when compared to the CTRL group (Fig. 3), which is in agreement with observations made by other researches under different ZLS etching times (Sato et al., 2016; Ramakrishnaiah et al., 2016; Traini et al., 2016). Initially, the HF etching acts on localized areas, promoting dissolution of only the glass matrix, revealing the lithium silicate/zirconia grains. As the etching time increases, the region of interaction increases as well, and the interaction involves the whole the surface (Fig. 3), as previously described by Ramakrishnaiah et al. (2016). At shorter etching times the defects introduced appear to be in a dimension and format that make it difficult for the cement to fill-up the irregularities, making bonding vulnerable to failure (as observed on $\mathrm{HF}$ $10 \%$ for $30 \mathrm{~s}$, Table 1 ). When the etching duration is longer, the surface becomes more homogeneous, due to extensive loss of the glassy matrix and pullout of lithium silicate/zirconia grains, facilitating the penetration of the resin cement that leads to optimized bonding and improves the fatigue performance (higher fatigue strength for $60 \mathrm{~s}$ and 90 s, when using 5 or $10 \%$ HF, Table 1).

No statistical significant effect of the etching duration was observed for $5 \% \mathrm{HF}$ acid concentration (Table 1). Independent of the etching time, $5 \%$ HF promotes a less aggressive conditioning, localized on the outer surface, causing the shape and size of the defects to be less prone to promote fatigue failures (Venturini et al., 2015a), leading a similar mean fatigue failure loads as $10 \% \mathrm{HF}$ acid for $60 \mathrm{~s}$. It may be hypothesized that higher fatigue failure loads might be obtained when using 5\% HF for etching times longer than $90 \mathrm{~s}$, as more aggressive surface alterations and stronger adhesion may be promoted (as the ones observed for $90 \mathrm{~s}$ of $10 \% \mathrm{HF}$ etching).

The formation of a proper surface topography for a long-term bond depends on the acid concentration (Della Bona and Anusavice, 2002) and the surface conditioning time (Addison, Marquis and Fleming, 2007). Our results support this statement and also highlight the importance of $\mathrm{HF}$ etching to promoting enhanced fatigue loads and achieve stable and durable adhesion (Venturini et al., 2015a; Sato et al., 2016; Sattabanasuk et al., 2016). Another important aspect that influences the long-term bond stability is silanization. It is known that silane application to the HF etched ceramic surface improves adhesion with resin cement (Sattabanasuk et al., 2016), promoting a chemical bond between ceramic and resin cement. At the same way, the use of an universal adhesive containing silane based primer also is able to contribute to the chemical bonding durability between both substrates (Tsujimoto et al., 2017).

All specimens from the CTRL group (without HF etching on the ceramic) demonstrated catastrophic failures due to debonding at ceramic-resin cement interface. This is due to the absence of HF acid etching and at the presence of highly polished surfaces. Silanized interfaces appear to be unstable in humid conditions, since siloxane bonds are susceptible to degradation by water absorption (Reuter and Brose, 1984; Matinlinna et al., 2004). This fact may be also responsible for the lower fatigue failure load values found for the control group in this study, when the hydrofluoric acid was not applied on the samples (i.e., no micromechanical interlocking), having only chemical adhesion, and may be the reason for the high rate of debonding at the cementing interfaces. It strongly limits the micro-mechanical bond between the resin cement and the ceramic (Xiaoping, Dongfeng and Silikas, 2014). The poor bonding may have also resulted in poorly disturbed load bearing (ceramic/cement/substrate) and, consequently, the stress concentrated onto the cementation surface of the ceramic (interface with resin cement) leading to the premature failure.

The substrate supporting material, used previously by Chen et al. (2014), was an epoxy filled with woven glass fibers, similar to G10 (woven glass fiber-filled epoxy - NEMA Grade G-10 rod; Piedmont
Plastics, Inc, Charlotte, a dentin analogue material previously validated by Kelly et al. (2010). This material was reported by Kelly et al. (2010) not to be different from hydrated dentin in terms of blunt contact elastic behavior or resin cement bond strength, and has an elastic modulus similar to that of dentin. Previous studies demonstrated sufficient compatibility between G10 and dentin, both in terms of adhesion and elastic/mechanic behavior. This synthetic material became the dentin substitute used to support ceramic specimens in all tests (Wang et al., 2007; Kelly et al., 2010). Hence, the trilayer model used in the present study played a crucial role on the fatigue performance, which included both substrates (ceramic and dentin analogue) as well as the adhesion between them (Chen et al., 2014). Although our model is a simplified set-up for fatigue performance screening, it can be expected that the same mechanism exists for more complex clinical dental restorations.

As described by Kelly et al. (1996) and supported by clinical trials (Thompson et al., 1994; Hickel and Manhart, 2001), the majority of glass-ceramic crown failures initiate from flaws and tensions existing at the cementation surface, indicating this surface is the location of the highest tensile stress and/or the largest flaws. All failures found in the current study consisted of radial cracks originating from surface defects, ascribed to defects generated with acid etching for etched samples and by processing for the CTRL group, on the center of the ceramic disc at the cementation (bonding) surface of the ceramic and propagating to the periphery of the ceramic disc, in agreement with previous studies (Quinn, 2007; May et al., 2015; Venturini et al., 2017). In fragile/brittle materials such as ceramics, the onset of fractures can occur from preexisting defects on the surface or inside the ceramic material and propagate under excessive stress (usually tensile stress) (Prochnow et al., 2017) (Fig. 4a-f).

It is important to elucidate some limitations of this in vitro study. Some clinical conditions were not reproduced such as sliding, which occurs during chewing or clenching, given the axial load was applied in the center of specimens. Also, the accelerated fatigue test was performed for a lifetime of 500,000 cycles and the outcomes may change under an extended number of cycles. Additionally, the fatigue failure load of samples etched in 5\% HF might be improved at times $>90 \mathrm{~s}$, which may lead to stronger alterations of the ceramic surface and promote the micro-mechanical retentions and resin bond improvements observed on $10 \% \mathrm{HF}$ etched samples.

\section{Conclusion}

Based on findings of this study, it can be concluded that for fatigue failure load improvement, the pre-treatment of $10 \% \mathrm{HF}$ acid etch for $60 \mathrm{~s}$ up to $90 \mathrm{~s}$, followed by the application of an adhesive that contains silane and MDP achieved the best performance. Additionally, etching with $5 \% \mathrm{HF}$ acid, independent of time ( $30 \mathrm{~s}, 60 \mathrm{~s}$ or $90 \mathrm{~s}$ ), was shown not to change the fatigue behavior of the zirconia-reinforced lithium silicate ceramic.

\section{References}

Aboushelib, M.N., Sleem, D., 2014. Microtensile bond strength of lithium disilicate ceramics to resin adhesives. J. Adhes. Dent. 16, 547-552. http://dx.doi.org/10.3290/ j.jad.a33249.

Addison, O., Marquis, P.M., Fleming, G.J., 2007. The impact of hydrofluoric acid surface treatments on the performance of a porcelain laminate restorative material. Dent. Mater. 23 (4), 461-468. http://dx.doi.org/10.1016/j.dental.2006.03.002.

Anami, L.C., Lima, J.M., Valandro, L.F., Kleverlaan, C.J., Feilzer, A.J., Bottino, M.A 2016. Fatigue resistance of Y-TZP/porcelain crowns is not influenced by the conditioning of the intaglio surface. Oper. Dent. 41 (1), E1-E12. http://dx.doi.org/10. 2341/14-166-L.

Anusavice, K.J., Hojjatie, B., 1992. Tensile stress in glass-ceramic crowns: effect of flaws and cement voids. Int. J. Prosthodont. 5, 351-358.

Campos, F., Valandro, L.F., Feitosa, S.A., Kleverlaan, C.J., Feilzer, A.J., de Jager, N., Bottino, M.A., 2017. Adhesive cementation promotes higher fatigue resistance to zirconia crowns. Oper. Dent. 42 (2), 215-224. http://dx.doi.org/10.2341/16-002-L.

Chen, C., Trindade, F.Z., de Jager, N., Kleverlaan, C.J., Feilzer, A.J., 2014. The fracture resistance of a CAD/CAM Resin Nano Ceramic (RNC) and a CAD ceramic at different thicknesses. Dent. Mater. 30 (9), 954-962. http://dx.doi.org/10.1016/j.dental.2014. 
05.018 .

Collins, J.A., 1993. Staircase or Up-and-down Methods. In_: Failure of Materials in Mechanical Design - Analysis, Prediction, Prevention, 2 ed. John Wiley \& Sons, New York, pp. 383-390.

Della Bona, A., Anusavice, K.J., 2012. Microstructure, composition, and etching topography of dental ceramics. Int. J. Prosthodont. 15 (2), 159-167.

Elsaka, S.E., Elnaghy, A.M., 2016. Mechanical properties of zirconia reinforced lithium silicate glass-ceramic. Dent. Mater. 32 (7), 908-914. http://dx.doi.org/10.1016/j. dental.2016.03.013.

Ferrario, V.F., Sforza, C., Tartaglia, G.M., Colombo, A., Serrao, G., 1999. Size and shape of the human first permanent molar: a Fourier analysis of the occlusal and equatorial outlines. Am. J. Phys. Anthropol. 108, 281-294.

Fraga, S., Pereira, G.K., Freitas, M., Kleverlaan, C.J., Valandro, L.F., May, L.G., 2016. Loading frequencies up to $20 \mathrm{~Hz}$ as an alternative to accelerate fatigue strength tests in a Y-TZP ceramic. J. Mech. Behav. Biomed. Mater. 61, 79-86. http://dx.doi.org/10. 1016/j.jmbbm.2016.01.008

Gonzaga, C.C., Cesar, P.F., Miranda Jr, W.G., Yoshimura, H.N., 2011. Slow crack growth and reliability of dental ceramics. Dent. Mater. 27 (4), 394-406. http://dx.doi.org/ 10.1016/j.dental.2010.10.025

Gracis, S., Thompson, V.P., Ferencz, J.L., Silva, N.R., Bonfante, E.A., 2015. A new classification system for all-ceramic and ceramic-like restorative materials. Int. J. Prosthodont. 28 (3), 227-235. http://dx.doi.org/10.11607/ijp.4244.

Harris, E.F., Hicks, J.D., 1998. A radiographic assessment of enamel thickness in human maxillary incisors. Arch. Oral Biol. 43, 825-831. http://dx.doi.org/10.1016/S00039969(98)00061-2.

Hickel, R., Manart, J., 2001. Longevity of restorations in posterior teeth and reasons for failure. J. Adhes. Dent. 3, 45-64.

Hooshmand, T., Parvizi, S., Keshvad, A., 2008. Effect of surface acid etching on the biaxial flexural strength of two hot-pressed glass ceramics. J. Prosthodont. 17 (5), 415-419. http://dx.doi.org/10.1111/j.1532-849X.2008.00319.x.

ISO, 6872, 2008. Dentistry - Dental ceramics. Int. Organ. Stand.

Kelly, J.R., Nishimura, I., Campbell, S.D., 1996. Ceramics in dentistry: historical roots and current perspectives. J. Prosthet. Dent. 75, 18-32. http://dx.doi.org/10.1016/S00223913(96)90413-8.

Kelly, J.R., Rungruanganunt, P., Hunter, B., Vailati, F., 2010. Development of a clinically validated bulk failure test for ceramic crowns. J. Prosthet. Dent. 104 (4), 228-238. http://dx.doi.org/10.1016/S0022-3913(10)60129-1.

Leite, F.P.P., Özcan, M., Valandro, L.F., Moreira, C.H.C., Bottino, M.A., Kimpara, E.T., 2013. Effect of the etching duration and the ultrasonic cleaning on microtensile bond strength between feldspathic ceramic and resin cement. J. Adhes. 89, 159-173. http://dx.doi.org/10.1080/00218464.2013.739024.

Matinlinna, J.P., Lassila, L.V.J., Özcan, M., Yli-Urpo, A., Vallittu, P.K., 2004. An introduction to silanes and their clinical applications in dentistry. Int. J. Prosthodont. 17 (2), 155-164.

May, L.G., Kelly, J.R., Bottino, M.A., Hill, T., 2012. Effects of cement thickness and bonding on the failure loads of CAD/CAM ceramic crowns: multi-physics FEA modeling and monotonic testing. Dent. Mater. 28, e99-e109.

May, L.G., Kelly, J.R., Bottino, M.A., Hill, T., 2015. Influence of the resin cement thickness on the fatigue failure loads of CAD/CAM feldspathic crowns. Dent. Mater. 31 (8), 895-900. http://dx.doi.org/10.1016/j.dental.2015.04.019.

Morimoto, S., Rebello de Sampaio, F.B., Braga, M.M., Sesma, N., Özcan, M., 2016. Survival rate of resin and ceramic inlays, onlays, and overlays: a systematic review and meta-analysis. J. Dent. Res. 95 (6), 1-10. http://dx.doi.org/10.1177/ 0022034516652848.

Özcan, M., Vallittu, P.K., 2003. Effect of surface conditioning methods on the bond strength of luting cements to ceramics. Dent. Mater. 19 (8), 725-731.

Pereira, G.K.R., Silvestri, T., Amaral, M., Rippe, M.P., Kleverlaan, C.J., Valandro, L.F., 2016. Fatigue limit of polycrystalline zirconium oxide ceramics: effect of grinding and low-temperature aging. J. Mech. Behav. Biomed. Mater. 61, 45-54. http://dx. doi.org/10.1016/j.jmbbm.2016.01.006.

Posritong, S., Borges, A.L., Chu, T.M., Eckert, G.J., Bottino, M.A., Bottino, M.C., 2013. The impact of hydrofluoric acid etching followed by unfilled resin on the biaxial strength of a glass-ceramic. Dent. Mater. 29, e281-e290.

Prochnow, C., Venturini, A.B., Grasel, R., Bottino, M.C., Valandro, L.F., 2017. Effect of etching with distinct hydrofluoric acid concentrations on the flexural strength of a lithium disilicate-based glass ceramic. J. Biomed. Mater. Res. B Appl. Biomater. 105
(4), 885-891, http://dx doi.org/10.1002/jbm.b.33619.

Quinn, G.D., 2007. NIST Recommended Practice Guide: Fractography of Ceramics and Glasses. National Institute of Standards and Technology, United States.

Ramakrishnaiah, R., Alkheraif, A.A., Divakar, D.D., Matinlinna, J.P., Vallittu, P.K., 2016. The effect of hydrofluoric acid etching duration on the surface micromorphology, roughness, and wettability of dental ceramics. Int. J. Mol. Sci. 17 (6), 1-17. http://dx. doi.org/10.3390/ijms17060822.

Reuter, J.E., Brose, M.O., 1984. Failures in full crown retained dental bridges. Br. Dent. J. 157 (2), 61-63.

Rinke, S., Pabel, A.-K., Rödiger, M., Ziebolz, D., 2016a. Chairside fabrication of an allceramic partial crown using a zirconia-reinforced lithium silicate ceramic. Case Rep. Dent. http://dx.doi.org/10.1155/2016/1354186.

Rinke, S., Rödiger, M., Ziebolz, D., Schmidt, A.-K., 2016b. Fabrication of zirconia-reinforced lithium silicate ceramic restorations using a complete digital workflow. Case Rep. Dent. http://dx.doi.org/10.1155/2016/1354186.

Sato, T.P., Anami, L.C., Melo, R.M., Valandro, L.F., Bottino, M.A., 2016. Effects of surface treatments on the bond strength between resin cement and a new zirconia-reinforced lithium silicate ceramic. Oper. Dent. 41 (3), 284-292. http://dx.doi.org/10.2341/14357-L.

Sattabanasuk, V., Charnchairerk, P., Punsukumtana, L., Burrow, M.F., 2016. Effects of mechanical and chemical surface treatments on the resin-glass ceramic adhesion properties. J. Investig. Clin. Dent. 1-9. http://dx.doi.org/10.1111/jicd.12220.

Sulieman, M., Addy, M., Rees, J.S., 2005. Surface and intra-pulpal temperature rises during tooth bleaching: an in vitro study. Br. Dent. J. 199, 37-40. http://dx.doi.org/ 10.1038 /sj.bdj. 4812558 .

Thompson, J.Y., Anusavice, K.L., Naman, A., Morris, H.F., 1994. Fracture surface characterization of clinically failed all-ceramic crowns. J. Dent. Res. 73, 1824-1832.

Traini, T., Sinjari, B., Pascetta, R., Serafini, N., Perfetti, G., Trisi, P., Caputi, S., 2016. The zirconia-reinforced lithium silicate ceramic: lights and shadows of a new material. Dent. Mater. J. 35 (5), 748-755. http://dx.doi.org/10.4012/dmj.2016-041.

Tsujimoto, A., Barkmeier, W.W., Takamizawa, T., Wilwerding, T.M., Latta, M.A., Miyazaki, M., 2017. Interfacial characteristics and bond durability of universal adhesive to various substrates. Oper. Dent. 42 (2), E59-E70. http://dx.doi.org/10. 2341/15-353-L.

Venturini, A.B., Prochnow, C., May, L.G., Bottino, M.C., Felipe Valandro, L., 2015a. Influence of hydrofluoric acid concentration on the flexural strength of a feldspathic ceramic. J. Mech. Behav. Biomed. Mater. 48, 241-248. http://dx.doi.org/10.1016/j. jmbbm.2015.03.025.

Venturini, A.B., Prochnow, C., May, L.G., Kleverlaan, C.J., Valandro, L.F., 2017. Fatigue failure load of feldspathic ceramic crowns after hydrofluoric acid etching at different concentrations. J. Prosthet. Dent. http://dx.doi.org/10.1016/j.prosdent.2017.03. 021. May 26. pii: S0022-3913(17)30237-8.

Venturini, A.B., Prochnow, C., Rambo, D., Gundel, A., Valandro, L.F., 2015b. Effect of hydrofluoric acid concentration on resin adhesion to a feldspathic ceramic. J. Adhes. Dent. 17, 313-320.

Villefort, R.F., Amaral, M., Pereira, G.K., Campos, T.M., Zhang, Y., Bottino, M.A. Valandro, L.F., de Melo, R.M., 2017. Effects of two grading techniques of zirconia material on the fatigue limit of full-contour 3-unit fixed dental prostheses. Dent. Mater. 33 (4), e155-e164. http://dx.doi.org/10.1016/j.dental.2016.12.010.

Vita Suprinity - Working Instructions. Vita Zanhfabrik 2013.

Wachtman Jr, J.B., Capps, W., Mandel, J., 1972. Biaxial flexure tests of ceramic substrates. J. Mater. 7, 188-194.

Wang, Y., Katsube, N., Seghi, R.R., Rokhlin, S.I., 2007. Statistical failure analysis of adhesive resin cement bonded dental ceramics. Eng. Fract. Mech. 74, 1838-1856. http://dx.doi.org/10.1016/j.engfracmech.2006.11.006.

Wiskott, H., Nicholls, J.I., Belser, U.C., 1995. Stress fatigue: basic principles and prosthodontic implications. Int. J. Prosthodont. 8 (2), 105-116.

Xiaoping, L., Dongfeng, R., Silikas, N., 2014. Effect of etching time and resin bond on the flexural strength of IPS e. max Press glass ceramic. Dent. Mater. 30 (12), e330-e336. http://dx.doi.org/10.1016/j.dental.2014.08.373.

Zimmermann, M., Mehl, A., Reich, S., 2013. New CAD/CAM materials and blocks for chairside procedures. Int. J. Comput. Dent. 16, 173-181.

Zogheib, L.V., Bona, A.D., Kimpara, E.T., McCabe, J.F., 2011. Effect of hydrofluoric acid etching duration on the roughness and flexural strength of a lithium disilicate-based glass ceramic. Braz. Dent. J. 22 (1), 45-50. 